\title{
FilOSOFÍA PARA/CON NiÑOS: ACOTACIONES HERMENÉUTICAS Y EJERCICIO DE APLICACIÓN
}

\section{PHILOSOPHY FOR/WITH CHILDREN: HERMENEUTICAL DIMESSIONS AND EXERCISES}

\author{
HumBerto GONZÁLEZ GALVÁN \\ Universidad Autónoma de Baja California Sur \\ hgonz@uabcs.mx
}

RECIBIDO: 15 DE OCTUBRE DE 2013

ACEPTADO: 10 DE ENERO DE 2014

\begin{abstract}
Resumen: En este escrito, se conversa de manera hermenéutica (Gadamer) con uno de los textos fundacionales de Filosofía para Niños $(\mathrm{FpN})$ que es ahora un clásico: La otra educación. Filosofía para niños y la comunidad de indagación (1996). Se analizan algunas objeciones recientes a FpN que fueron anticipadas y hasta "resueltas" desde este texto. Por último, se incluye un ejercicio de FpN utilizando de manera experimental un poema y no una novela, que es lo que se suele utilizar de manera convencional.
\end{abstract}

Palabras clave: Filosofía para niños, educación, hermenéutica, un ejercicio poético.

Summary: In this writing we talk, in a hermeneutical way (Gadamer), with one of the foundational texts of Philosophy for Children (PfC) which is right now a classical one: Teaching for better thinking. The classroom community of inquiry (1995). We discuss also some recent objections to PfC that we think are well solved in this text. Finally, we also included an experimental exercise of PfC using a poem as a fresh start to think with, and not the most conventional entry point: a novel.

Keywords: Philosophy for children, education, hermeneutics, a poetical exercise.

\section{Apertura mística}

Sentado en un cómodo sillón, en plena sala del Centro Latinoamericano de Filosofía para Niños. A.C. sito en las faldas de un frondoso cerro boscoso de San Cristóbal de las Casas (Chiapas, México); con su director, el Dr. Eugenio Echeverría casi frente a mí, trabajando; con su secretaria Araceli en un escritorio a mi izquierda, trabajando; con Feliciano revoloteando de aquí para allá, trabajando; con doña Tere acomodando platos y limpiando la cocina, trabajando; con don Mateo allá afuera en el jardín siguiendo borregos, trabajando; con un a medias presente Jaime, trabajando a su manera; con las parejas Leslie-Fernando y Sandra-Guillermo y sus pequeños respectivos críos: José Pablo, Maximiliano y Gonzalo, de los primeros y Mauricio, de los segundos, todos ellos también yendo 
y viniendo para empezar el día y emprender alguna salida en estas sus vacaciones familiares... estando esto así como digo, y siendo aproximadamente las diez de la mañana de este martes 23 de julio, declaro inaugurado ad-hoc este Diplomado personalizado de Filosofía para Niños (o lo que resulte). Mejor ambiente de trabajo no hubiera podido imaginar ni en mis mejores sueños. Así sea, pues, y éxito en esta empresa de abstracciones y concreciones deliciosas.

\section{Presentación "problemática"}

Al debate en torno a la preposición "para" o "con" hay que darle su justo lugar. Ya Ann Sharp y Lawrence Splitter en su libro de 1995 (La otra educación) afirman lo siguiente:

En este libro intentamos demostrar qué significa hacer filosofía con niños. Esperamos, de este modo, justificar muchas de las afirmaciones clave: que los niños pueden hacer filosofía, que deben hacer filosofía y que la filosofía está en el corazón mismo de la educación ${ }^{1}$.

En este sentido, la radical contraposición que realiza Fernando Betancourt en su por otro lado excelente recuento histórico de esta aproximación filosófica a la infancia, no debe llevarse a extremos conceptuales. Quizá sólo se trate de estrategias de contacto que, y en ello coincidimos todos (empiristas demócratas o dialécticos), sean necesariamente múltiples y diversas. Lo que sí vale la pena declara e incluso ejercitar como debate con los mismos niños, es la importancia de las palabras (en este caso "con" y/o "para").

En torno a la idea de "comunidad de indagación" transcribamos lo siguiente:

Una comunidad de indagación es a la vez inmanente y trascendente: proporciona un marco que impregna la vida cotidiana de sus participantes y sirve como un ideal por el cual esforzarse. No está unida a ninguna disciplina específica: hay comunidades de indagación científica, histórica, literaria y del medio ambiente, tanto como comunidades de indagación estética, ética y epistemológica (esto es, filosóficas) -y a menudo estas están entrelazadas, en la medida en que los estudiantes de una disciplina son llevados por su propia indagación a penetrar en otras ${ }^{2}$.

Los autores abundan en este concepto (comunidad de indagación) citando a John Dewey:

\footnotetext{
${ }^{1}$ SPLITTER, Lawrence Joseph, SHARP, Ann Margaret: La otra educación. Filosofía para niños y la comunidad de indagación, Editorial Manantial, Buenos Aires, 1996, p. 18. Cursivas de los autores.

${ }^{2}$ Ibíd., p. 36.
} 
La indagación es la transformación controlada o directa de una situación indeterminada en una que es tan determinada en sus distinciones y relaciones constitutivas que convierte los elementos de la situación original en un todo unificado. $^{3}$

Agregan al respecto: "La indagación puede ser creativa tanto como crítica. No queremos excluir el tipo de indagación sobre las formas y posibilidades en las que se embarca un artista."

También es importante el contacto crítico de este enfoque de indagación con la psicología genética de Jean Piaget. Nos dicen Splitter y Sharp:

No queremos analizar la posición esencialmente conservadora de Piaget acerca del entendimiento conceptual de los niños. Lo que sí afirmamos es que los niños pequeños pueden entregarse $\mathrm{y}$ de hecho se entregan al pensamiento abstracto (incluyendo el establecimiento de conexiones entre el pensar concreto y el pensar abstracto), como lo evidencian sus interacciones sociales y lingüísticas con sus pares. El hecho de que existan y prosperen las comunidades de indagación entre niñas y niños de 6-8 años refuta cualquier hipótesis o teoría en contrario. ${ }^{5}$

De hecho, pues, Filosofía para Niños ( $\mathrm{FpN}$ ) incorpora (eso creo) un piagetismo abierto a la construcción interactiva concreto-abstracto, interacción que por cierto es válida también para la indagación significativa de cualquier adulto.

En lo personal, me gusta la metáfora que se le atribuye a Mathew Lipman respecto a la idea de "progreso" que se da en toda indagación cooperativa. Este progreso sería algo así como:

el progreso de un velero que cambia de curso según el viento, más que el de una flecha que vuela infaliblemente hacia un blanco fijo y predeterminado. $\mathrm{Si}$ bien el yate puede no tomar parte de una caravana hacia la meta, finalmente arriba, sin embargo, a algún sitio. Empero, esta meta no puede ser determinada antes del arribo. / Del mismo modo, la comunidad de indagación debe "seguir la indagación hacia donde esta va". La indagación cooperativa es un proceso de "un paso adelante, uno atrás y dos a los costados", en el que los participantes mismos se hacen responsables de su dirección general”"

\footnotetext{
${ }^{3}$ Ibíd., p. 52. Tomado de DEWEY, John, Logic: the theory of inquiery, Henry Holt \& co., N.Y., 1938.

${ }^{4}$ Ibídem.

${ }^{5}$ Ibíd., p. 41.

${ }^{6}$ Ibíd., pp. 45-46.
} 
Veo este proceso "progresivo" del todo semejante al proceso de la conversación que el filósofo Hans-Georg Gadamer defiende como modelo de la comprensión hermenéutica. Así también en éste es el espíritu del lenguaje el que lleva la batuta y marca el ritmo hacia las cosas de que se está hablando-indagando, cuando este habar de ellas es, en efecto, significativo. También conecta con la hermenéutica gadameriana el hecho de que...

El concepto de "persona razonable" está en el núcleo de Filosofía para Niños y, se puede sostener, de la educación misma y del ideal de democracia. ${ }^{7}$

A este respecto ("persona razonable") Gadamer dedica toda la primera parte de su libro clave (Verdad y método) rescatando todo un elenco de conceptos humanísticos que muy bien se pueden asimilar a la "razonabilidad" que Splitter y Sharp aquí sustentan: “...(buen) pensar, sentido, cuidado, juicio y personalidad..."8 Gadamer hace lo propio con conceptos tales como formación (Bildung), sentido común y comunitario (sensus communis), sensibilidad, tacto estético y gusto (Geschmack), capacidad de juicio (Urteilskraft), prudencia (phrónesis $)^{9}$. En todo caso es claro que la "razonabilidad" no excluye a la razón, pero sí la desborda integrando aspectos como los señalados.

De igual manera, veo un importante contacto hermenéutico con $\mathrm{FpN}$ cuando se auspicia la creatividad (que siempre es significativa) por sobre la mera repetición de fórmulas hueras. En este sentido Splitter y Sharp distinguen el conversar del dialogar, siendo ensalzado este último, el dialogar, en aras a la creatividad que direcciona. Aunque es también (como en el caso de las preposiciones "para" o "con") cuestión de términos (ahora "conversar" o "dialogar"), las coincidencias de fondo son claras: la conversación (en Gadamer) y el diálogo (en FpN) coinciden en el proceso creativo libre que se ve direccionado a la manera de un velero (la anterior metáfora de Lipman).

Hasta aquí, puedo considerar cuatro problemas "resueltos" y son los siguientes:

1.- el problema proposicional "con" o "para",

2.- el diálogo FpN y constructivismo piagetiano,

3.- el asunto de los materiales: o ad-hoc (novelas ex-profeso) o novelas, cuentos, poemas "clásicos" 10

\footnotetext{
${ }^{7}$ Ibíd., p. 22.

${ }^{8}$ Ibíd., p. 23.

${ }^{9}$ Cfr. GADAMER, Hans Georg: Verdad y método. Fundamentos de una hermenéutica filosófica, Editorial Sígueme, Salamanca, 1993. Sobre todo "Significación de la tradición humanística para las ciencias del espíritu" (pp. 31-71).

${ }^{10}$ De este "problema", no se ha dicho nada aquí, de manera directa. Su "solución" se verá un poco más adelante. De momento baste indicar que las novelas ex-profeso que impulsa FpN tienen que ver con el hecho de que sus "instructores" no son necesariamente filósofos y, en este sentido, conviene
} 
4.- Énfasis de FpN en el "diálogo" (por su estructuración) vs. el énfasis conceptual de la hermenéutica (gadameriana) en la "conversación" (justo por su "falta de estructuración").

\section{Generalidades interpretadas}

Para FpN educación no es lo mismo que capacitación, y es bueno que así sea (cfr. nota 46 en p. 172). En este sentido se emparejan muy bien educación y formación, afianzada ésta última por Gadamer como bastión filosófico de la hermenéutica, más allá de habilidad técnica alguna. Muy a la Wittgenstein nos señalan al respecto Splitter y Sharp:

son centrales las preguntas filosóficas como: " $¿ Q u e ́$ me hace ser la persona que soy?", “Cómo puedo saber que algo es cierto?” y “¿Cómo debería vivir?”11

FpN también enfatiza el vínculo entre libertad y razonabilidad (más que racionalidad, a la que incluye, como antes se dijo). El apoyo para esta vinculación se encuentra en Pierce:

Esto es, la persona puede, o, si les gusta, se ve obligada a hacer más razonable su vida. ¿Qué otra idea distinta a ésta me alegraría saber que puede ser relacionada con la palabra "libertad"? ${ }^{12}$

Sentar desde la "más tierna infancia" conceptos filosóficos a través de su indagación en aspectos cotidianos de la vida es, en el fondo, retornar al origen "natural" de la filosofía en las calles de Grecia...

Los conceptos filosóficos están incorporados en todas las disciplinas. Pero preguntar acerca de conceptos como causa, espacio, tiempo, hipótesis, teoría y ley es distinto de preguntar cómo funciona de hecho el mundo de acuerdo con ellos. Responder esto último implica valerse de modos científicos de indagación como la observación, la formación de hipótesis, la predicción y la experimentación. Cuando los niños preguntan acerca del significado de los conceptos científicos - por encima de investigar cómo se aplican éstos en la práctica- están haciendo filosofía (en este caso, filosofía de la ciencia). ${ }^{13}$

$\mathrm{Al}$ sostener $\mathrm{FpN}$ que la construcción del sentido se da a la manera de una suerte de "traducción" (p. 181), abona a la búsqueda y establecimiento de

mantener muy bien estructurados en manuales ad-hoc la guía de las indagaciones respectivas.

${ }^{11}$ Ibíd. pp. 162-163.

${ }^{12}$ Citando un trabajo de SHARP: "Pierce, feminism and philosophy for children" (Analytic teaching 14:1, p.p. $51-62)$.

${ }^{13}$ Ibíd. p. 181. 
asociaciones personales significativas, con lo que integra así las experiencias subjetivas en la base misma del conocimiento... "Sentido, no certeza, es lo que los niños reclaman." 14

\section{Consideraciones de técnica}

Distinguir entre cierre procedimental y cierre sustantivo es algo importante a tener en cuanta. El último es imposible, el primero, necesario (p. 184). Este tipo de cierres son, cada uno a su manera, "anticipaciones". Así les llaman los autores y lo encuentro congruente con lo que en hermenéutica se da en términos de doble anticipación, donde una anticipación tiene que ver con la perfección de aquello que se está "viendo" (teorizando) y la otra anticipación tiene que ver con la finitud de ser mortales y no poder alcanzar jamás, por ello, un final último en lo indagado. Algunos problemas que pueden aquí suscitarse, tanto procedimentales como sustantivos, tienen que ver justo con tener de antemano conclusiones predeterminadas (p. 188). A este respecto resulta muy ilustrativa la metáfora de Otto Neurath: "podemos reparar un barco en alta mar, pero no podemos hacerlo si intentamos reemplazar todas sus piezas a la vez" (p. 218). En efecto, no hay nada sagrado, todo es motivo de indagación filosófica (como las piezas del barco a reparar), sea en lo sustantivo o sea en lo procedimental, pero hay que ir por partes. Y en esta sistemática averiguadora, el profesor no puede predeterminar resultado alguno (no obstante mantener su inevitable "doble anticipación" hermenéutica, a manera de la atención flotante freudiana). Es por ello que al profesor se le suele designar más bien con metáforas de lo más significativas: motivador, provocador, docente-interventor, administrador, facilitador, entrenador, tejedor, tábano, partero, en fin, se hace de él modelo de "ignorancia erudita" en su "despliegue autoconsciente de una genuina curiosidad y perplejidad, más que de la impresión de estar siempre en lo "correcto". ${ }^{15}$

Una habilidad que el tábano o partero (para usar los nombres que Sócrates se asignaba a sí mismo en su docta ignorancia) debe cultivar, es la de "tener oído" (p. 192) para los temas filosóficos que vayan surgiendo en el camino. Es desde este oído fino desde donde van a ir surgiendo las preguntas de indagación (PI's) que hay que seguir. Esta "conciencia de posibilidades filosóficas" es la que será para él guía para ir construyendo en comunidad.

\footnotetext{
${ }^{14}$ Ibíd. p. 186.

${ }^{15}$ Ibíd., p. 192, aunque los autores asignan este giro metafórico a Whitehead y, luego, a Reed en diversas publicaciones.
} 
a) Razonamientos e indagación.

b) Formación de conceptos.

c) Construcción de sentido.

Nos dicen Splitter y Sharp:

Reconocemos que en estas primeras etapas del crecimiento de la comunidad, invitar a los estudiantes a hacer preguntas basadas en lo que hallan interesante en un relato, un poema, una obra de teatro o una ilustración podría no ser muy fructífero. Los niños más grandes tienden a recibir tal invitación con una sospecha que surge de una larga experiencia en la que los docentes hacen PRs, los niños PCs y nadie Pis. No es que carezcan de la habilidad para hacer preguntas, sino de las disposiciones asociadas de la curiosidad y una mentalidad abierta. Por otra parte, los niños muy pequeños -en quienes la curiosidad y el asombro están usualmente presentes en abundancia- pueden so saber cómo preguntar. En ambas situaciones, el docente debe desplegar su sensibilidad al contexto y actuar en consecuencia: usará narraciones y otros materiales de estímulo susceptibles de atrapar adolescentes cínicos, y luego les mostrará que sus preguntas y preocupaciones serán tomadas en serio; alternativamente, estimulará a los niños a que articulen lo que tengan en mente -sea en la forma de una pregunta o no-, tal vez, haciéndoles preguntas abiertas apropiadas (de la forma “¿Qué es lo que nos estamos preguntando?”). Las observaciones y los comentarios pueden también aportar la chispa para una posterior indagación, especialmente cuando tienen preguntas incorporadas en ellos ${ }^{16}$

Aunque lo anterior muy bien pude llevarse a cabo con materiales existentes ya en la tradición literaria (relatos, poesía, novela, etc.), lo argumentado aquí se inclina al diseño de materiales ex-profeso, como los que se han venido elaborando por Mathew Lipman y Ann Sharp, y que incluyen extensos manuales para el tábanopartero que los aplique ${ }^{17}$. A manera de ejercicio, incluyo un anexo al final de este escrito, en el que ensayo un breve trabajo filosófico partiendo de un poema de Joan Manuel Serrat (Mi niñez).

En fin, que para FpN resulta más importante contestarse en visión retrospectiva la pregunta ¿qué aprendimos? que el desarrollo de un plan de tareas en perspectiva a abonarse a alguna lejana meta por alcanzar (cfr .p. 196):

\footnotetext{
${ }^{16}$ Ibíd., pp. 193-194. Las siglas PCs, Pis y PRs utilizadas por los autores, corresponden a Preguntas Corrientes, Preguntas de investigación y Preguntas retóricas, respectivamente.

${ }^{17}$ Un argumento adicional en favor del uso de estos materiales, es que el tábano-partero no debe tener necesariamente una formación filosófica académica, por lo que el desglose exhaustivo conceptos, sentidos y razonamientos filosóficos vertidos en los manuales de acompañamiento, resultan de suma utilidad y guía.
} 
[El tábano-partero] tiene la autoridad que un guía o un piloto tiene en relación con el capitán de un barco, más que la suma de la autoridad del capitán y el piloto en relación con los pasajeros ${ }^{18}$

Ahora bien, ya avanzada en su integración, una comunidad de investigación:

Los estudiantes comienzan a ver cuestiones y conceptos filosóficos en artículos de diarios, libros instruidos, otros materiales de ficción, programas de televisión, videos, libros de texto tradicionales y cuando reflexionan sobre sus propias experiencias. Y los docentes comienzan a hallar nuevos modos de estructurar discusiones en clase y de generar el tipo de preguntas que estimulan el pensamiento filosófico ${ }^{19}$

Lo importante es motivar la indagación filosófica ahí donde el entorno ofrezca el mínimo motivo para ello (que suele hacerlo en casi toda actividad humana), más que atenerse a opiniones dogmáticas o a rígidos objetivos preestablecidos, más producto de "ignorancia activa" (p. 228) que de indagación auténtica. Esto nos lleva ahora al área de la investigación ética (religiones incluidas), ya que en ella se dan de manera muy evidente las necesidades de contexto y conexión a fin de emitir juicios razonables vinculados a situaciones complejas:

En el contexto de una comunidad de indagación, los hechos particulares de los antecedentes religiosos y culturales de los niños no son ni más ni menos importantes que su pertenencia a una sociedad que tiene ciertos puntos de vista y comparte ciertas tradiciones científicas, históricas, literarias y artísticas. Del mismo modo, no son más ni menos importantes que el hecho de que los niños (la mayoría de) nacen y son educados por otros que tienen interese creados en su desarrollo personal y ético. Es obligación de todos aquellos que afirman tener tales derechos (muy en especial padres y maestros) garantizar que los niños mismos, con todo lo que consideran importante y valioso, sean participantes plenos y conscientes en ese desarrollo ${ }^{20}$

Continúan más adelante los autores, enfatizando el aspecto aplicado de FpN en una de sus áreas más sensibles:

Convertir la clase en una comunidad de indagación filosófica requiere de una práctica creciente de virtudes morales e intelectuales: justicia, tolerancia, cuidado, amistad, veracidad, coraje, humildad, lealtad, amabilidad,

\footnotetext{
${ }^{18}$ Ibíd. p. 196, citando a YOUNG, Robert: Critical thinking and classroom talk, Ing. Multilingual matters Ltd., Clevedon, 1992, p. 103.

${ }^{19}$ Ibíd. p. 198.

${ }^{20}$ Ibíd. p. 230.
} 
benevolencia, paciencia, compasión, dignidad, persistencia, respeto por las personas, amor propio, libertad e integridad personal. Aprender a ser es como aprender a hablar, pensar y escribir. Una vez que se incorporan unos cuantos conceptos, reglas y procedimientos elementales, lo que resta es "hacerlo" una y otra vez de un modo reflexivo y autocorrectivo, y con mucha ayuda de nuestros amigos. En términos que fueron antes preponderantes en la educación moral, los valores y las virtudes deben ser tanto "enseñados" como "captados": pueden ser discutidos, analizados y explorados pero, en última instancia, deben ser practicados, incorporados y vividos. Aquí vemos la conveniencia de la comunidad filosófica: la filosofía es la disciplina apropiada para "enseñar" valores, y la comunidad el ámbito apropiado para "captarlos"21

Los anteriores argumentos quieren "corregir" en cierta medida la ética deliberativa de Aristóteles, cuyo "exceso" de racionalismo tendría que atenuarse justo por una aplicación razonable de eso deliberado:

Al trabajar con el concepto de razonabilidad (más que con el de razón), no sólo evitamos algunas de las dificultades que enfrenta la concepción en exceso racionalista de Aristóteles, sino que ponemos en juego los aspectos disposicionales e interpersonales de la formación del carácter que la comunidad de indagación hace tanto por desarrollar y fomentar. ${ }^{22}$

Redondeamos estas ideas éticas de FpN con otra larga cita que, así creemos, no tiene desperdicio:

El desafío ético que enfrenta la escuela es precisamente el que hace suyo la comunidad de indagación: fortalecer y enriquecer la vida de las niñas y los niños, de modo que puedan vivir mejor y responder a las muchas y variadas - pero no siempre constructivas- fuentes de presión con las que se enfrentan. La presión de los pares que se alimentan de estereotipos de masculinidad y feminidad, coraje y lealtad; la necedad y el anti intelectualismo inquietantes de los videos de música y la televisión comercial; la marejada de la tecnología de la computación; la explotación de los jóvenes por inescrupulosos traficantes de drogas, pornografía y productos escolares que tienen que ver poco con la educación y mucho con ayudar a las grandes corporaciones a ganar dinero, y una sociedad que mide el valor de un ser humano por la naturaleza de su trabajo en una era de desempleo crónico: porque las personas hacia las que están dirigidas ya no están dispuestas a aceptarlas sin discusión. ${ }^{23}$

\footnotetext{
${ }^{21}$ Ibíd. p .241.

${ }^{22}$ Ibídem.

${ }^{23}$ Ibíd., p .244.
} 


\section{De variopinta temática}

Diversidad y apertura: FpN trata de "...construir, sino un punto de vista unificado, sí una comprensión más clara de muchos puntos de vista diferentes" (p. 259). Y más adelante se nos indica que la comunidad de indagación "debe seguir la indagación hacia donde vaya" (p. 263) ${ }^{24}$, lo que, como dijimos algunas páginas antes, responde vis a vis, en claro paralelismo, al concepto hermenéutico de conversación que esgrime Gadamer como modelo de comprensión, justo por su carácter abierto hacia la móvil estela de tradición que acompaña a cada asunto a indagar hablando de él.

Indagación no es lo mismo que terapia: una diferencia clave consiste en la necesaria dirección impuesta tanto por el terapeuta como por los grupos de encuentro en los que los participantes se exponen de manera directa. No, en la indagación filosófica son los procedimientos y asuntos sustantivos los que centran la atención grupal y, además, de manera cada vez más autodirigida y autogestionada (cfr. p. 270).

Violencia y sociedad: muchas veces la violencia incluye valores positivos que vale la pena indagar razonable y racionalmente, así como códigos morales alternativos que también merecen ser explorados (cfr. p. 270 y ss.):

Una comunidad de indagación no ofrece soluciones inmediatas a los problemas sociales: no puede dar trabajo durante una recesión ni acallar las aspiraciones violentas de aquellos que derribarían la misma democracia que los tolera. Pero los fanáticos y traficantes de odio de todo el mundo conocen de sobra la importancia de ganarse el apoyo ciego y acrítico de todos aquellos que quieran escucharlos. Aquí, pues, reside el beneficio y el sentido de transformar las clases en comunidades de indagación: ofrecer a los jóvenes los recursos para hablar, escuchar, pensar y valorar y luego decidir qué es lo justo y razonable. ${ }^{25}$

'es’ no implica 'debe ser' (p. 276).

\section{FpN y feminismo}

Filosofía para niños y la filosofía feminista hacen hincapié en una pedagogía que implica cuidado, diálogo y búsqueda de sentido. Rechazan las dicotomías rígidas de la emoción y la razón, el conocedor y lo conocido, el cuerpo y la mente, la teoría y la práctica. Reconocen la importancia de atender a contextos específicos

\footnotetext{
${ }^{24}$ Más adelante se nos dice a este respecto: "Ser serio en cuanto a la formación de una comunidad de indagación es mostrarse preparado a seguir la indagación adonde ésta lleve” (p. 291).

${ }^{25}$ Ibíd. p. 273.
} 
y de vincular las categorías y las metodologías filosóficas a juicios de valor, y niegan la posibilidad de una teoría no valorativa así como la de una objetividad pura y neutral... Además, ambas prestan atención a la conversación corriente cotidiana - con su informalidad, su dimensión metafórica, su vaguedad y ambigüedad- y ambas instan a la teoría a crecer y ser corregida de forma constante por la práctica de la reflexión diaria. ${ }^{26}$

De nuevo, hago ver la coincidencia entre $\mathrm{FpN}$ y hermenéutica filosófica en cuanto a la importancia otorgada a la conversación que, en Gadamer, se eleva al rango de modelo de comprensión.

\section{FpN y ambientalismo}

Existen comunidades de indagación ambiental que, grosso modo, se pueden distinguir entre críticas-analíticas y creativas-constructivas. En general, sus enfoques coinciden en un bio o eco-centrismo de algún tipo en el que se reconoce el valor moral de la vida en general (cfr. p. 304). Se emparejan así con el eco-feminismo, con FpN y con una así llamada "ecología profunda". Se trata de una auténtica...

Visión del mundo "como una comunidad en la cual los individuos se definen unos a otros a través de sus relaciones recíprocas y con el suelo, el agua, la atmósfera y otros elementos no vivientes del medio ambiente que proveen el tejido que mantiene unida a la comunidad". ${ }^{27}$

Hay que indicar un matiz, no sé qué tan importante, entre FpN y ecofeminismo. Lo señalan Splitter y Sharp: FpN propone en primer lugar al ser humano, a la persona en toda su diversidad y complejidad ética, mientras que el eco-feminismo coloca en primera instancia a la tierra en su más amplia vinculación ética. La siguiente cita de Robert C. Fuller abre una posible salida de compromiso:

Lo que distingue un acto como moral es que contribuye al bien de maneras que se fortalecen y alimentan a lo largo del tiempo y a través de la comunidad. La racionalidad moral traduce el cuidado humano en una jerarquía de compromisos y obligaciones que establece una clara prioridad de aquellos "bienes" (necesidades, deseos, intereses) que contribuyen al beneficio a largo plazo de los individuos y del ecosistema en que habitan. ${ }^{28}$

Por su parte, Lorraine Code nos dice:

\footnotetext{
${ }^{26}$ Ibíd. pp. 273-274.

${ }^{27}$ Ibíd., p. 305; citando a MATTHEW (1990): "Submission on environmental inquiry".

${ }^{28}$ Ibíd., p. 308; citando el libro de FULLER: The ecology of care.
} 
Las amenazas de disolución no provienen sólo de los peligros de aniquilación nuclear y de contaminación y agotamiento ambiental, sino también de las estructuras y prácticas sociales que son sistemáticamente injustas, discriminatorias, distantemente autoritarias y basadas en los principios de competitividad, dominación e interés personal que sirven a una minoría privilegiada a expensas de las minorías menos favorecidas... Los valores centrados en la preservación, en el vivir armoniosamente unos con otros y con la biosfera - no pasiva, sino creativa y comunitariamente- gozan de una alta estima dentro del pensamiento ecologista y crean una continuidad entre los movimientos ecologistas y los movimientos pacifistas a lo largo del mundo ${ }^{29}$

y también con la comunidad de indagación, agregan Splitter y Sharp (p. 309).

\section{Proponemos, dicen estos autores:}

una visión del niño como indagador: un pensador crítico, creativo y solícito que está tan capacitado como dispuesto a autocorregirse, y que se ve a sí mismo como uno ente otros en un intento colaborador de construir el sentido y el conocimiento ${ }^{30}$

Comunidad es la palabra clave y, a través de ella, con ella y en ella, la filosofía como puerta de entrada privilegiada a la construcción del sentido. Se piensa así a la infancia como un estado del ser y un estado del devenir, de manera simultánea. John Dewey sirve de apoyo pedagógico conceptual a estas ideas:

Siempre vivimos en el tiempo en que vivimos y no en algún otro, y solamente si extraemos el sentido completo de cada experiencia presente en cada momento presente estaremos preparados para hacer lo mismo en el futuro. Esta es la única preparación que, en el largo plazo, significa algo ${ }^{31}$

\footnotetext{
${ }^{29}$ Ibíd., p. 309; citando a CODE, Lorraine: What can she know: feminist theory and the construction of knowledge, Cornell U. Press, Ithaca, N.Y., 1991). En este texto, de corte epistemológico, como se echa de ver el título mismo, tenemos, de acuerdo a Splitter y Sharp, que Lorraine “...sostiene que pensar y saber deben ser vistos en el contexto de las interrelaciones entre los que piensan, los que saben y las 'innumerables relaciones, acontecimientos, circunstancias e historias que hacen que del que sabe y de lo sabido lo que son, en ese momento"” (p. 309).

${ }^{30}$ Ibíd., p. 323.

${ }^{31}$ Esta cita de Dewey se encuentra como epígrafe del capítulo 3 de la obra de Splitter y Sharp que estamos siguiendo (p. 97), junto a otro epígrafe de E.M. Forster: ¡Relaciona!
} 


\section{Comunidad global, ciudadanía global}

En la indagación así globalizada, lo básico siguen siendo las preguntas y lo que ellas desencadenan en términos de diálogo $(\mathrm{FpN})$ o conversación (hermenéutica), abriéndose a nuevas preguntas $\mathrm{y}$, con ellas, un mejor conocimiento de sí mismos:

Partícipes de una creciente comunidad internacional de indagación, las niñas y los niños tendrán la oportunidad de construir un concepto más amplio de sí mismos, una visión y una idea más amplias del propósito que tenga en cuenta las preocupaciones y las perspectivas de otros al considerar las consecuencias de sus propias acciones sobre el mundo ${ }^{32}$

\section{Cierre}

Se busca o, mejor, se construye con los propios niños su bienestar en el mundo. Bienestar espiritual, ético e intelectual (p. 327):

Urgimos a todos aquellos que se interesan y se preocupan por los jóvenes a verse a sí mismos como partícipes de una indagación continua, en la clase, en sus hogares, y en las redes y foros de pares donde se abordan y ponen en relación temas de filosofía y pedagogía. E invitamos a quienes comparten nuestra visión de lo que las niñas y los niños son y pueden ser, a trabajar juntos -en comunidad- para que esa visión se transforme en realidad. / La indagación filosófica en las manos, las mentes y los corazones de los niños y las niñas es una perspectiva enormemente emocionante. Basta con preguntarles a ellos ${ }^{33}$

Nos quedamos, pues, con esta invitación de Lawrence Splitter y Ann Margaret Sharp. Mejores palabras no podrían acabar, dejando abierto, este breve trabajo de resumen y conversación hermenéutica.

\footnotetext{
${ }^{32}$ Ibíd., p. 326.

${ }^{33}$ Ibíd., p. 328.
} 


\section{Anexo I}

\section{El Centro de Desarrollo "Pequeño Sol”}

El ejercicio que aquí vamos a describir fue desarrollado de manera amplia y experimental, en dos grupos de cuarto y quinto grado de primaria, aunque también se exploró de manera mínima su aplicación con un grupo de segundo grado de secundaria. La escuela donde se llevó a cabo esta experiencia fue el Centro de Desarrollo "Pequeño Sol", sito en San Cristóbal de las Casas (Chiapas, México). Hay que indicar que este centro educativo mantiene desde sus inicios, hace ya casi treinta años, a la FpN como una de sus líneas pedagógicas más importantes. Sus distintos grupos se ejercitan en $\mathrm{FpN}$ dos veces a la semana. Creemos conveniente dar ahora una descripción general de dicha escuela. ${ }^{34}$

Aunque en la página web del Centro de Desarrollo "Pequeño Sol" se consigna la siguiente leyenda de entrada: "Al llegar a esta escuela me gustó para quedarme, porque no parece una escuela", debemos decir que en la realidad este tipo de consignas son sumamente móviles y se transforman con frecuencia. Así, leímos, por ejemplo, en la entrada a la Ludoteca, el siguiente mensaje recién puesto y del que estaba orgullosa la profesora Alicia Miranda Arteaga: "Ante todo lo demás, está la infancia. Las huellas de los primeros años, los que deciden para siempre lo que se va a hacer." Pero así como este mensaje, aparecen otros y otros; unos más duraderos (como los puestos en algún mural que decidió dejar como recuerdo una generación de egresados ("Todos vivimos bajo el mismo cielo, pero todos tenemos un distinto horizonte"); otros más transitorios, como los que se colocan en la pizarra de la "cafetería filosófica" de la escuela.

Así entonces, el Centro de Desarrollo "Pequeño Sol" es una Asociación Civil sin fines de lucro que se fundó en 1984, gracias al esfuerzo de algunas madres y padres de familia que quisieron crear una alternativa educativa donde todos los niños y niñas sin importar su cultura, religión, clase social, convivieran y se respetara su identidad; una Escuela al servicio de la comunidad y para la comunidad En la Escuela Pequeño Sol se ofrece servicio educativo en las áreas de Maternal, Preescolar, Primaria y Secundaria. Sé también que hace algún tiempo se tiene proyectado abrir grupos de nivel preparatoria, pero que este reto no ha terminado de concretarse todavía. La escuela está, en todos sus niveles, incorporada a la Secretaría de Educación Pública y asociada también a la UNESCO. Se dispone de un Programa de Becas para quienes desean estudiar ahí, pero que tienen dificultades económicas.

\footnotetext{
${ }^{34}$ La información que aquí glosamos proviene de la página web del propio Centro, a donde ahora remitimos: http://www.pequenosol.org, último acceso 25 de julio de 2013.
} 
En este 2013 la escuela celebra 29 años funcionando como centro educativo. Cabe calcular, por tanto, 27 generaciones de preescolar, 24 generaciones de primaria y 21 generaciones de secundaria. Se ha venido trabajando con un promedio de poco más de 300 alumnos.

De forma permanente se capacita al propio personal docente en actualizaciones que implican la revisión de herramientas de trabajo y de Planeación Estratégica. Hay que señalar que, a últimas fechas, el Centro también proporciona servicios de capacitación a personal docente proveniente tanto de otras partes de Chiapas, como de otros estados de la República.

La Misión del "Pequeño Sol" es la siguiente:

"Formar a personas autónomas y responsables consigo mismas, con los demás y con su entorno"...

...siendo su Visión:

"Consolidar en San Cristóbal una alternativa educativa que equilibre una alta calidad académica y formación integral de la persona, abierta a la diversidad social y cultural"

Teniendo la solidaridad comunitaria como uno de sus principios rectores, se muestran congruentes y, eso, solidarios con toda necesidad de formar personas capaces de contribuir en la construcción de un mundo mejor: otro mundo es posible y no tiene porqué no ser mejor.

Las Bases metodológicas que conforman este proyecto educativo en marcha son:

(A) Currículum Social: Desarrollo de habilidades socio-afectivas, creación de una comunidad escolar segura, prácticas de actitudes de autonomía, disciplina personal y respeto, transformación creativa de los conflictos en oportunidades de aprendizaje.

(B) Promoción de la lectura y escritura: Acercamiento a los libros y el gusto por la lectura, desarrollo de habilidades de comprensión de diversos textos, desarrollo de habilidades de expresión escrita.

(C) Filosofía para niños y niñas: Desarrollo de un pensamiento crítico, creativo y ético, formación de comunidades de diálogo.

(D) Expresión Creativa: Psicomotricidad, expresión corporal, representación plástica, música, danza, teatro.

(E) Procesos de investigación: Apropiación de diversos métodos de investigación científica y documental, fomento de un sentido de asombro hacia el mundo.

Especial interés y énfasis en: 
- $\quad$ Problemas mundiales y búsqueda de soluciones

- $\quad$ Aprendizaje intercultural: Comprensión y apreciación de otras culturas

- Educación para la paz: Derechos humanos y democracia

- Educación ambiental: el ser humano y el medio

- Educación sexual y enfoque de género.

Es en el contexto de este Centro Educativo, "Pequeño Sol", tan receptivo a la experimentación pedagógica que tenga a la filosofía como motor de iniciativas creadoras, fue que nos atrevimos a proponer la práctica que ahora se describe. Conscientes de lo incompleto y perfectible de lo realizado, nos impulsó una idea básica de doble vertiente: (1), se puede partir de materiales poéticos, con niños de todas las edades, para desde ellos impulsar preguntas y diálogos de indagación filosófica, y; (2), partir de materiales poéticos es una estrategia especialmente importante y adecuada, para estudiantes universitarios de formación filosófica. Con estas anticipaciones a cuestas, anexamos ahora un primer ejercicio de FpN utilizando, en este caso particular, un poema de Joan Manuel Serrat como punto de partida indagatorio:

\section{Ser-tener: ejercicio de Filosofía... ¿para niños? Presentación}

De manera convencional la estructura pedagógica que impulsaron sobre todo Matthew Lipman y Ann M. Sharp en términos de Filosofía para Niños ${ }^{35}$ (FpN), plantea, como material de arranque, un texto narrativo escrito ex-profeso, una novela. A partir de dicho texto se delimitan toda una serie de ejercicios que ponen en contacto al niño con diversos temas filosóficos, siempre en un lenguaje accesible a las edades correspondientes de los niños, y siempre siguiendo los principios metodológicos de una comunidad de indagación filosófica, es decir, abriendo sus diversos sentidos a través del diálogo. Nosotros aquí, siguiendo estos mismos principios conversacionales, proponemos estructurar una práctica semejante de FpN, pero esta vez en torno a un poema. La "narratividad" de un poema, por supuesto, no es la misma que la de una novela. Tampoco estamos aquí pensando en una aplicación de esta propuesta dialógica a poblaciones

\footnotetext{
35 Superamos el escollo conceptual que algunos académicos plantean en términos de oposición radical y excluyente a partir de la mera disyunción preposicional o 'para' o 'con', citando a la propia Ann Sharp: "En este libro intentamos explicar y demostrar qué significa hacer filosofía con niños. Esperamos, de este modo, justificar muchas de las afirmaciones clave: que los niños pueden hacer filosofía, que deben hacer filosofía y que la filosofía está en el corazón mismo de la educación" (SPLITTER, Lawrence Joseph y SHARP, Ann Margaret: La otra educación. Filosofía para niños y la comunidad de indagación, Editorial Manantial, Buenos Aires, 1996, p. 18. Las cursivas del texto son de los autores).
} 
exclusiva y principalmente infantiles, aunque sí que queremos poner ello a prueba de manera más que experimental. Confesamos que esta idea (partir de poesía) surgió por principio de considerar a poblaciones universitarias con formación filosófica, que son las poblaciones en las que nosotros solemos movernos de manera profesional cotidiana; hay que decir que, muchas veces, esta poblaciones no distinguen la conexión entre conceptos abstractos de la tradición filosófica con sus referentes vitales en la vida cotidiana. De ahí que busquemos propiciar dicha articulación, fundamental en la consecución propia del sentido, desde una articulación semejante entre lo dicho en representaciones imaginarias (poemas) y lo desarrollado en representaciones conceptuales (filosofemas).

Así pues, el poema que vamos a trabajar con base metódica FpN se llama "Mi niñez". El poeta que lo compuso es el canta-autor catalán Joan Manuel Serrat. Esta canción-poema apareció originalmente en 1970, en un álbum que lleva por nombre el mismo que el del autor: Joan Manuel Serrat.

Ser-tener: ejercicio de Filosofía... ¿para niños? Desarrollo

Se sugiere una primera lectura del poema completo. Puede no convenir en grupos de niños muy pequeños (aunque esto es muy variable y depende de muchas variables), por lo que se pueden ensayar distintas formas de presentación lectora. Lo que conviene, de manera estratégica, es elaborar una visión general del poema punto de partida.

Mi niñez (Joan Manuel Serrat).

Tenía diez años y un gato

peludo, funámbulo y necio

que me esperaba en los alambres del patio

a la vuelta del colegio.

Tenía un balcón con albahaca

y un ejército de botones

y un tren con vagones de lata

roto entre dos estaciones.

Tenía un cielo azul y un jardín de adoquines

y una historia a quemar temblándome en la piel.

Era un bello jinete

sobre mi patinete

burlando cada esquina

como una golondrina

sin nada que olvidar

porque ayer aprendí a volar, 
perdiendo el tiempo mirando el mar.

Tenía una casa sombría que madre vistió de ternura y una almohada que hablaba y sabía de mis sueños de ser cura.

Tenía un canario amarillo que al viento trinaba sus penas oyendo algún viejo organillo o mi radio de galena.

Y en julio, en Aragón, tenía un pueblecillo, una acequia, un establo y unas ruinas al sol.

Al viento los ombligos volaban cuatro amigos picados de viruela y huérfanos de escuela, robando uva y maíz, chupando caña y regaliz.

Creo que entonces yo era feliz.

Tenía cuatro sacramentos y un ángel de la guarda amigo y un "Paris-Hollywood" prestado y mugriento escondido entre los libros.

Tenía una novia morena que abrió a la luna mis sentidos jugando los juegos prohibidos a la sombra de una higuera.

Crucé por la niñez imitando a mi hermano.

Descerrajando el viento y apedreando al sol.

Mi madre crió canas pespunteando pijamas, mi padre se hizo viejo sin verse en el espejo, y mi hermano se fue de casa, por primera vez.

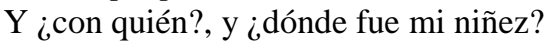

Ser-tener: ejercicio de Filosofí... ¿para niños? Instructivo de análisis e indagación

Hasta aquí el poema. Ahora, siguiendo la estructura convencional de los manuales que acompañan las novelas de Filosofía para Niños ${ }^{36}$, proponemos la

\footnotetext{
${ }^{36}$ Tengo a mano, en traducciones al castellano y adaptaciones diversas, los siguientes materiales:
} 
siguiente guía para moderar y orientar las indagaciones filosóficas a partir del poema leído (y quizá hasta escuchado, ya que se cuenta con interpretaciones musicales del poema que, en este caso concreto, nacieron a la par que el poema en manos de su canta-autor). Para ello conviene, ahora sí, concentrarse en secciones de imágenes y/o versos, fragmentados de manera conveniente de acuerdo a la idea filosófica que se desee indagar.

Ser-tener: ejercicio de Filosofía... ¿para niños? Idea principal: Tener y Ser.

Tener y ser han sido tratados en filosofía de múltiples maneras. Desde el clásico Tener o ser del psicólogo Erick Fromm, hasta el Étre et avoir del teólogo Gabriel Marcel, pasado por el marxista Balthasar Staehelin y su Haben und Sein. ¿Tener o ser?, ¿tener y ser?, ¿tener para ser o ser para tener?, ¿irreconciliables, intermitentes o progresivos (ya sea en un sentido o en otro)?. Veamos en resumen una de las ideas de Marcel al respecto:

a través de algunas cuestiones sobre el problema del tiempo se enuncia que el sujeto no es pura receptividad, porque se puede decir que a la hora de que un sujeto se encuentra aprehendiendo algo, que en cierto sentido se está dando simultáneamente, no solamente hay una abstracción o una aprehensión, sino también un acontecer. Por tanto, dentro del dinamismo inteligible hay una mayor comprensión de lo que se aprehende cuando se está activamente asociado a él y no se es un simple espectador. Ante esto, Marcel indica que cuanto "más tratemos al mundo como un espectáculo necesariamente más debe llegar a sernos metafísicamente ininteligible; y esto porque la relación misma que se establece entonces entre nosotros y él es intrínsecamente absurda". ${ }^{37}$

Así pues, por lo menos y como punto de partida, tenemos aquí un argumento a favor de interconectar tener y ser en términos metafísicos... ¿cómo se podría discutir esta idea a partir de las imágenes y expresiones del poema arriba transcrito?

Hospital de muñecos y Sian y Carlota (Ann M. Sharp); Elfie (Matthew Lipman); Hannah (A. Sharp); Kio y Gus (M. Lipman); Pixie (M. Lipman); El descubrimiento de Filio Episteme (M. Lipman); Lisa (M. Lipman) y Mark (M. Lipman). Todas estas novelas están acompañadas con sus correspondientes manuales para el moderador y abarcan, grosso modo, desde el jardín de niños hasta el nivel de lo que en México corresponde a la preparatoria.

${ }^{37}$ El texto entrecomillado corresponde a MARCEL, Gabriel: Ser y tener, Editorial Caparrón, Madrid, 1996, pp. 7-8; la tomamos de Filosofía contemporánea. Blog universitario de análisis, reseñas y comentarios sobre filosofía contemporánea:

http://textosfil.blogspot.mx/2012/01/algunos-rasgos-de-la-obra-ser-y-tener.html 
Ser-tener: ejercicio de Filosofía... ¿para niños? Plan de discusión y diálogo ${ }^{38}$

1.- ¿Cómo podemos distinguir con claridad (o no se puede) entre tener una edad y tener un animal o una cosa?

2.- Tener diez años y ser un niño de diez años, ¿es lo mismo?

3.- Cuando se tiene más edad (o se es más grande), ¿se tienen más memoria o menos?

4.- ¿Qué es la memoria y cómo se comporta con los recuerdos en el tiempo?

5.- ¿Cómo puede uno saber si fue feliz alguna vez?

6.- ¿Qué es la felicidad?

7.- ¿Es lo mismo tener una novia que estar enamorado?

8.- ¿cuál es la diferencia y/o en qué se parecen?

9.- ¿Qué es del Ser en cada caso (ser novio, ser enamorado)?

10.- ¿Cuándo se pasa de ser niño a ser joven o a ser adulto o viejo?

11.- A los padres y a los hermanos mayores, ¿hay que imitarlos?

12.- ¿Qué es el tiempo?

13.- ¿A dónde se va el tiempo que somos?

14.- ¿Cabe la pregunta con quién se fue nuestro tiempo?, ¿o es lo mismo que preguntar dónde se fue nuestro tiempo?

Ser-tener: ejercicio de Filosofia ... ¿para niños? Ejercicio ${ }^{39}$

Se eligen tres niños que representarán ante sus compañeros los siguientes personajes: (a) un gato, (b) un niño (o niña), dueño(a) del gato, y (c) el papá (o mamá) de ese niño (o niña). ${ }^{40}$

Para empezar, cualquiera de los tres personajes (a), (b) o (c) ${ }^{41}$ lee un fragmento del poema, por ejemplo:

Tenía diez años y un gato

peludo, funámbulo y necio

\footnotetext{
${ }^{38}$ Una observación del Dr. Eugenio Echeverría nos hizo notar lo apretado de este Plan de Discusión y Diálogo, pudiendo, por las diversas temáticas, haberse ampliado de manera analítica muchísimo más de lo que aquí se apunta.

${ }^{39}$ Este ejercicio está pensado para los niños de cuarto y quinto grado de primaria, que fue con quienes se trabajó. Para otras edades y, por supuesto, para estudiantes universitarios, los ejercicios prácticos posibles tendrían que pensarse en muy otro sentido.

${ }^{40}$ De manera adicional, la sola decisión del género de estos papeles puede generar, por sí misma, temas adicionales de diálogo e indagación.

${ }^{41} \mathrm{Y}$ conviene que en cada nuevo fragmento se rote el personaje lector.
} 
que me esperaba en los alambres del patio a la vuelta del colegio

Enseguida, inician entre ellos una indagación acerca de qué es tener diez años y qué es tener un gato, e incluso acerca de qué es tener un hijo y qué es tener una mascota; también acerca de qué es tener una casa y qué significa que la casa tenga un patio ( $i$ es lo mismo que una casa tenga un patio a que un gato sea peludo?, por ejemplo). Y así se puede esperar que, luego de ejercitarse en combinatorias de clases y conjuntos, se vayan haciendo distinciones y semejanzas a partir de las diversas imágenes que nos va proponiendo el poema a medida que avanza.

\section{Vocabulario $^{42}$}

Funámbulo: acróbata que hace ejercicios en cuerda o en alambre. El gato al que hace referencia el poema es, en este sentido, y a menos que me equivoque, un gato atípico, cosa que se corresponde al tono paralelista e irónico general del poema.

Patinete: en México se les conoce mejor como "patín del diablo".

Radio de galena: receptor de AM muy primitivo y sencillo, para captar señales de onda media y corta. Puede fabricarse de manera artesanal y no requiere energía.

Cuatro sacramentos: de acuerdo al catolicismo en el que se pone en contexto el poema y a la edad en la que sitúa el "yo poético", estos serían el bautismo, la confesión-penitencia, la eucaristía y la confirmación.

Paris-Hollywood: es una revista erótica popular para adultos en los años cincuenta y sesenta del siglo XX. De relativamente bajo presupuesto, si se la compara con las actuales ediciones para "caballeros". Se entiende, pues, que un niño tuviese que esconder el manoseado ejemplar que tenía.

Descerrajar: La palabra en sí no tiene confusión alguna (forzar una cerradura o quitar un cerraje), aunque su historia remite a los serrallos otomanos y a los harenes musulmanes que, según la fantasía occidental, encerraban a sus mujeres y concubinas para tenerlas alejadas de miradas imprudentes. En el poema sólo se alude a la proeza de forzar no cerraduras, sino al viento, colocando al "yo poético" en un plano de idealismo rebelde.

\footnotetext{
${ }^{42}$ En el poema se emplean giros y palabras poco comunes en México, por lo que se decidió agregar este vocabulario mínimo que en la práctica ha resultado no sólo útil, sino que además ha abierto debates adicionales vinculados a las diferencias culturales propias de una misma lengua en distintas latitudes.
} 


\section{Bibliografía}

El libro con el que aquí conversamos de manera hermenéutica es el siguiente: SPLITTER, Lawrence Joseph y SHARP, Ann Margaret: La otra educación. Filosofía para niños y la comunidad de indagación, Editorial Manantial, Buenos Aires, 1996.

Tuvimos a la mano los siguientes materiales para una permanente consulta, sin embargo no quisimos complicar en demasía nuestra redacción entrando en detalles extraídos de ellos:

GARCÍA MOYRÓN, Félix (ed): Matthew Lipman. Filosofía y educación, Ediciones de la Torre, Madrid, 2002.

KOHAN, Walter y WAKSMAN, Vera (compiladores): ¿Qué es filosofía para niños? Ideas y propuestas para pensar la educación, Editorial UBA, Buenos Aires, 1997.

VV.AA: La filosofía. Una escuela para la libertad. Enseñanza de la filosofía y aprendizaje del filosofar: la situación actual y las perspectivas para el futuro, Organización de las Naciones Unidas para la Educación, la Ciencia y la Cultura. UAM-Iztapalapa, México, 2011. 


\section{COMENTARIOS, \\ INFORMES Y \\ ENTREVISTAS}

\section{STUDIES, REPORTS AND INTERVIEWS}


